\title{
Use of rapid diagnostic techniques in ICU patients with infections
}

\author{
Almudena Burillo $0^{1,2,3}$ and Emilio Bouza $a^{1,2,3,4^{*}}$
}

\begin{abstract}
Background: Infection is a common complication seen in ICU patients. Given the correlation between infection and mortality in these patients, a rapid etiological diagnosis and the determination of antimicrobial resistance markers are of paramount importance, especially in view of today's globally spread of multi drug resistance microorganisms. This paper reviews some of the rapid diagnostic techniques available for ICU patients with infections.
\end{abstract}

Methods: A narrative review of recent peer-reviewed literature (published between 1995 and 2014) was performed using as the search terms: Intensive care medicine, Microbiological techniques, Clinical laboratory techniques, Diagnosis, and Rapid diagnosis, with no language restrictions.

Results: The most developed microbiology fields for a rapid diagnosis of infection in critically ill patients are those related to the diagnosis of bloodstream infection, pneumonia -both ventilator associated and non-ventilator associated-, urinary tract infection, skin and soft tissue infections, viral infections and tuberculosis.

Conclusions: New developments in the field of microbiology have served to shorten turnaround times and optimize the treatment of many types of infection. Although there are still some unresolved limitations of the use of molecular techniques for a rapid diagnosis of infection in the ICU patient, this approach holds much promise for the future.

Keywords: Rapid diagnosis, Clinical laboratory techniques, Intensive care unit, Microbiology

\section{Review}

\section{Background}

Although intensive care units (ICUs) have fewer than ten percent of the total number of beds in most hospitals, more than 20 percent of all nosocomial infections are acquired in ICUs and carry substantial morbidity, mortality, and expense [1-4]. The most common clinically significant infections observed in the ICU are intravascular catheter-related bloodstream infection (CR-BSI), ventilator associated pneumonia (VAP), and catheter associated urinary tract infection (CA-UTI).

In addition, multidrug-resistant (MDR) pathogens are evermore frequently isolated in ICUs $[5,6]$ and this hinders the initiation of appropriate, effective antibiotic therapy, which correlates with excess mortality [7-9].

\footnotetext{
* Correspondence: emilio.bouza@gmail.com

${ }^{1}$ Clinical Microbiology and Infectious Diseases Department, Hospital General Universitario Gregorio Marañón, Doctor Esquerdo 46, 28007 Madrid, Spain ${ }^{2}$ Instituto de Investigación Sanitaria Gregorio Marañón, Madrid, Spain
} Full list of author information is available at the end of the article
In this setting, a rapid etiologic microbiological diagnosis is mandatory. This paper reviews some of the rapid diagnostic techniques available for ICU patients with infections.

\section{Main text}

Rapid diagnosis of catheter-related bloodstream infections (CR-BSI)

A diagnosis of CR-BSI should be based on microbiological identification of the catheter as the source of bloodstream infection, and may be performed with or without catheter removal [10].

Attempts to establish the role of the catheter in episodes of BSI are justified by the following: a high proportion of the suspicious of CR-BSI are note confirmed after catheter removal and culture [11], and many CR-BSI can be managed empirically without immediately removing the catheter [12-14]. Central venous catheter (CVC) 
removal limits vascular access, and diagnostic methods exist that do not require catheter removal [15].

\section{Rapid procedures that do not require catheter removal}

The conservative approach to CR-BSI diagnosis (i.e., without catheter withdrawal) is highly convenient. Conservative procedures include differential paired quantitative blood cultures (comparison of colony counts in peripheral vein blood versus catheter hubs), superficial cultures (semiquantitative cultures of skin around the portal of entry and of catheter hubs), and a method comparing time to positivity between concurrent blood cultures of peripheral vein and catheter hub samples, named "differential time to positivity" (DTTP) [16-18].

\section{Paired central/peripheral cultures}

A ratio or differential colony count $\geq 3: 1 \mathrm{cfu} / \mathrm{mL}$ of bacteria from the catheter-drawn blood cultures compared to percutaneously-drawn blood cultures is usually accepted as a prove of CR-BSI. This cutoff shows a sensitivity (Se) of around $80 \%$ and specificity (Sp) of $90-100 \%$ [19].

Blood should be drawn from all hubs, representing the different catheter lumens [20]. This technique is usually performed with lysis-centrifugation tubes. Blood is inoculated in tubes containing the cell-lysing agent saponin, followed by vortexing and centrifugation. Then, after removing the supernatant (lysate), the concentrate is plated on agar medium and the plates incubated overnight before counting. The tubes need to be processed within 8 hours of inoculation [21]. Drawbacks of this technique include: the manual and individual processing of each individual sample, the risk of contamination, the risk of exposure of laboratory technicians to blood and the high cost [19].

\section{Differential time to positivity (DTTP)}

DTTP supporting CRBSI diagnosis is defined as a difference in time to positivity of $\geq 2 \mathrm{~h}$ between a CVC blood culture and a peripheral blood culture, or between 2 CVC blood cultures from different lumens of a multilumen catheter $[10,22,23]$. The DTTP test is conducted using a continuous-monitoring automated blood culture system. This method requires inoculating the same amount of blood in each culture bottle. For multiple lumen catheters, blood should be drawn from all ports $[20,24]$. To ensure accurate results, the first milliliters of blood drawn from the catheter should be used for culture. Then, bottles must be sent to the laboratory and incubated as soon as they arrive there. Depending on the type of catheter (short- $v$ s. long-term) and the patient, the test shows a Se of $86-93 \%$, Sp of $87-92 \%$, positive predictive value (PPV) of $85-88 \%$ and negative predictive value (NPV) of $89-95 \%[22,24,25]$.
DTTP is nowadays the main technique to assess CR-BSI used in most microbiology departments. Caution in interpretation should be applied in patients receiving antimicrobial agents [22]. The validity of DTT, however, has been recently questioned by Kaasch et al. [26]., that found a poor diagnostic performance (Se 37\%, Sp 77\%, PPV 46\%, NPV 70\%, validity 63\%) in patients with CR-BSI caused by Staphylococcus aureus. However, they failed to adhere to instructions of utmost importance related to the protocol. The microbiology service was not available on a $24 / 7$ basis, suggesting long pre-incubation periods before introducing the bottles in the automated blood culture machine, possibly leveling times to positivity of paired cultures, thus invalidating the diagnostic procedure $[27,28]$.

Our group recently demonstrated that the DTTP threshold applied to bacterial CR-BSI is not applicable in cases of CR-BSI caused by Candida spp. [29].

\section{Superficial cultures (combined exit-site and hub cultures)}

We call "superficial cultures" to the combination of semiquantitative cultures independently obtained from the $2 \mathrm{~cm}$ of skin surrounding the catheter insertion site and the various hubs.

The threshold for positivity of these semiquantative cultures is $15 \mathrm{cfu}$ per plate.

Growth of $<15$ cfus per plate of the same microbe from both the insertion site culture and catheter hub/s culture/s strongly suggests that the catheter is not the source of the BSI. Superficial cultures are justified only in cases of suspected CR-BSI (targeted cultures) in which they serve to rule out CR-BSI owing to their high sensitivity and good negative predictive value [16].

Gram staining of skin and hub swabs may also be helpful for the rapid diagnosis of CR-BSI [30].

Recently Bouza et al. compared the use of paired blood cultures, superficial cultures and DTTP for the diagnosis of CR-BSI without catheter removal [31]. DTTP showed a better sensitivity and negative predictive capacity than paired blood cultures to detect catheter tip colonization $(96.4 \%$ and $99.4 \%$ vs. $71.4 \%$ and $95.6 \%$, respectively) (Table 1). However, central/peripheral paired blood cultures showing a ratio $>5: 1$ provided the best specificity (97.7\%) for a diagnosis of CR-BSI. The three tests showed a high negative predictive capacity. If a negative result was obtained in any of the three tests, it was possible to rule out catheter colonization and CR-BSI reasonably well.

\section{Rapid diagnosis of sepsis}

The diagnosis of BSI among critically ill patients is a major challenge. Blood cultures are still considered the gold standard diagnostic procedure since pathogens may be isolated and subjected to antibiotic susceptibility testing (AST). In effect, the use of blood cultures in septic shock 


$\begin{aligned} & \text { Table } \mathbf{1} \text { Validity indices } \\
& \text { bloodstream infection }\end{aligned}$
\begin{tabular}{llll}
\hline Measure & $\begin{array}{l}\text { Semiquantitative superficial } \\
\text { cultures }\end{array}$ & $\begin{array}{l}\text { Differential quantitative } \\
\text { blood cultures }\end{array}$ & $\begin{array}{l}\text { Differential time to } \\
\text { positivity }\end{array}$ \\
\hline Sensitivity & $78.6(59.0-91.7)$ & $71.4(51.3-86.8)$ & $96.4(81.7-99.9)$ \\
Specificity & $92.0(87.0-95.6)$ & $97.7(94.3-99.4)$ & $90.3(85.0-94.3)$ \\
Positive predictive value & $61.1(43.5-76.9)$ & $83.3(62.6-95.3)$ & $61.4(45.5-75.6)$ \\
Negative predictive value & $96.4(92.4-98.7)$ & $95.6(91.4-98.1)$ & $99.4(96.6-99.9)$ \\
Accuracy & $90.2(85.3-93.9)$ & $94.1(90.0-96.9)$ & $91.2(86.4-94.7)$ \\
\hline
\end{tabular}

From reference [31].

patients as part of the compliance with six or more interventions of the 6-hour resuscitation bundle of the "surviving sepsis campaign" has been related to a reduction in mortality [32].

Blood cultures, however, are time-consuming and slow. They only detect viable microorganisms and show a low sensitivity for slow growing, intracellular and fastidious microorganisms. Overall positivity may be as low as 30$40 \%$ despite proper implementation of standard procedures, adequate blood volume collection and a high clinical suspicion of BSI.

Molecular techniques are ever-evolving to provide faster and more sensitive results along with the direct identification of responsible pathogens [33-36]. These techniques are likely to impact soon clinical decision-making and antibiotic treatment.

Existing commercial nucleic acid testing (NAT) diagnostic tests are all based on a similar procedure: pathogen lysis, nucleic acid extraction and purification, amplification of nucleic acids by PCR, and identification by various methods, such as ELISA-based hybridization, fluorescencebased real-time detection, liquid or solid phase microarray detection, sequencing and database recognition [34]. The reader is referred to Afshari et al. [34] for a comprehensive review of the tests commercially available today.

Pathogen-specific assays are even capable of detecting genes encoding resistance to antibiotics, such as mecA in staphylococci or van genes in enterococci.

A recent meta-analysis on the use of LightCycler SeptiFast revealed a Se and Sp of $80 \%$ and $95 \%$, respectively, for this technique to detect bacteremia, and of $61 \%$ and $99 \%$, respectively, to detect fungemia [36]. However, the bacteremia outcome subgroup showed high variation. The turnaround time of the technique was 6 hours.

In general terms, there are still important shortcomings of molecular techniques. For instance, the lack of an appropriate gold standard since blood cultures are unable to detect many true cases of infection; emphasis on microbiological rather than clinical assessment; no guidance for targeting appropriate clinical situations; and the potential for wrong interpretation of results if no expert assistance is available $[37,38]$.
Ideally, tests should provide relevant information 2-6 hours after samples are taken on which to base the choice of treatment. Under real-life conditions, there are often considerable delays due to practical issues, such as availability of staff outside daily routines or batch analysis of samples [39]. Test sensitivity needs to be improved to detect clinically relevant low bacterial loads and fastidious microorganisms. They should be able to distinguish between living and dead bacteria, especially for patients on antibiotics. They should also be able to clarify the impact of DNAemia in cases of clinical signs of BSI. For instance, in a recent paper on the combined use of blood cultures and SeptiFast to predict complicated BSI in cases of staphylococcal or Candida infection, the authors found that patients with a positive SeptiFast result between days 3 and 7 after a positive blood culture had an almost 8-fold-higher risk of developing a complicated bloodstream infection [40].

At present, molecular tests are used to complement the results of traditional culture, especially in serious clinical situations such as ICU patients with severe sepsis [37]. They also have the potential to be a cost-effective strategy to manage sepsis [41]. However, conventional blood cultures remain necessary because of the high incidence of multidrug-resistant bacteria in ICU patients and the need for AST to establish adequate treatment.

\section{Other helpful rapid tests for the diagnosis of sepsis}

Matrix assisted laser desorption/ionization time-of-flight (MALDI-TOF) mass spectrometry (MS) serves to identify isolated colonies of bacteria and fungi, and can also be used directly on positive blood culture broths in under one hour after the technician has been alerted of growth. This procedure is now replacing biochemical and gene sequencing methods for organism identification because it is easily implemented, highly accurate, inexpensive and fast [42-44]. Some 5 to $10 \mathrm{ml}$ of broth from a single positive blood culture bottle are needed for this technique. However, in most reports to date, identification yields are greater for Gram negative organisms than Gram positives or yeasts. To improve diagnosis, different sample preparation methods for positive blood 
cultures have been tested. Most of these methods include preincubation with different detergent concentrations (e.g., $5 \%$ saponin, $5 \%$ sodium dodecyl sulfate -SDS-, $0.1 \%$ Tween 80) or use of the Sepsityper kit (Bruker Daltonik $\mathrm{GmbH}$, Bremen, Germany) $[45,46]$.

In a recent study conducted at our center, we assessed the use of MALDI-TOF MS as a routine method for the identification of microorganisms directly from positive blood culture bottles (BCB) [47]. The turnaround time for results ranged from 20 to 30 minutes, similar to that reported in other studies. Analysis by bacteremia episode led to the complete identification of 814 out of 1000 episodes $(81.4 \%)$. As expected, Gram negative microorganisms were better identified than Gram positives or yeasts. However, by comparing spectral peaks we were able to differentiate between Streptococcus pneumoniae and Streptococcus mitis or Streptococcus oralis.

MALDI-TOF MS identification is available for clinicians within hours of a working shift, as opposed to $18 \mathrm{~h}$ for a conventional identification method. Moreover, although further improvement of sample preparation for polymicrobial $\mathrm{BCBs}$ is required, the identification of more than one pathogen in the same $\mathrm{BCB}$ provides a valuable indication of unexpected pathogens when their presence may remain undetected by Gram staining.

It has already proved useful for improving the adequacy of antibiotic treatment of bacteremia [48].

\section{Diagnostic and prognostic biomarkers in sepsis}

More than 180 molecules have been described as potential biological makers of sepsis. These molecules include C-reactive protein (CRP), procalcitonin (PCT), several cytokines, and cell surface markers [49], though only $20 \%$ have been assessed for use in the diagnosis of sepsis [50].

C-reactive protein was first described in the early 1930s. This acute phase protein is released by the liver in response to inflammation or tissue insult and is widely used as a highly nonspecific marker of sepsis. In a study by Póvoa et al. performed in 112 ICU patients, a serum CRP $>8.7 \mathrm{mg} / \mathrm{dl}$ showed a Se of $93 \%$ and $\mathrm{Sp}$ of $86 \%$ to detect the presence of infection. Adding a temperature $>38.2^{\circ} \mathrm{C}$ to this threshold increased Sp to 100\% [51].

The latter authors also observed that CRP concentrations increased over time in patients with infection, yet remained unchanged in non-infected patients. A daily CRP variation of at least $4.1 \mathrm{mg} / \mathrm{dl}$ was predictive of nosocomial infection with a Se of $92 \%$ and Sp of $71 \%$; when combined with a serum CRP above $8.7 \mathrm{mg} / \mathrm{dl}$, these values increased to 92 and $82 \%$, respectively [52]. Similarly, in patients with CRP concentrations $>10 \mathrm{mg} / \mathrm{dl}$ on ICU admission, a decrease in CRP after $48 \mathrm{~h}$ was linked to a mortality rate of $15 \%$, while its increase was associated with a mortality rate of $61 \%(\mathrm{p}<0.05)$ [53].
The peptide procalcitonin is synthesized by monocytes that are in the process of adhesion. PCT levels rise when there is local or systemic bacterial infection but not in the presence of a virus or autoimmune disease. Thus, PCT is more specific than CRP for detecting bacterial infection.

In a recent prospective study, on day 1 after admission to a medical-surgical ICU, a cut-off PCT $>1.39 \mathrm{ng} / \mathrm{ml}$ showed the best area under the curve (AUC) for diagnosing sepsis $(87 \%)$ and levels were found to significantly drop from day 1 to day 2 in survivors [54]. In addition, high PCT levels have been linked to an increased risk of mortality. As an example, in a recent prospective multicentre observational study performed in 1156 Greek in-patients, a PCT $>0.85 \mathrm{ng} / \mathrm{ml}$ was associated with $45 \%$ mortality in ICU patients [55]. It would appear that as for CRP, trends in PCT observed over time are more useful than single measurements [56].

However, we have yet to find a marker specific enough to provide a true diagnosis of BSI. The Surviving Sepsis Campaign 2012 guidelines state that the utility of PCT levels or other biomarkers to differentiate acute inflammatory patterns of sepsis from other causes of generalized inflammation (e.g., postoperative, other forms of shock) remains to be demonstrated [57].

\section{Rapid diagnosis of ventilator-associated pneumonia}

Hospital-acquired pneumonia (HAP), especially ventilatorassociated pneumonia (VAP), is one of the leading causes of infection and death in the ICU [58-62]. The incorrect or delayed treatment of HAP within a few hours gives rise to a worse prognosis and a higher mortality rate [63-65]. Useless antibiotics are also a cause of adverse events and unnecessary expense [66]. Thus, the etiologic diagnosis of VAP is a microbiological emergency because of its impact on the morbidity and mortality of this disease.

Bacterial identification and AST take 2 or 4 days, so there is a need for rapid diagnostic procedures. Rapid information is clearly more beneficial to the patient than more complete but delayed information. Gram staining, quantifying microorganisms in polymorphonuclear cells in bronchoalveolar lavage samples, and antibiograms conducted directly on clinical samples may provide information that correlates with subsequent culture results.

New diagnostic techniques, such as real-time PCR assays and "in situ" hybridization of bacteria, have been developed to speed up the identification of the pathogens responsible for this disease $[67,68]$.

\section{Lower respiratory tract samples for microbiology}

All patients suspected of having VAP should undergo lower respiratory tract (LRT) sampling followed by a microscopy examination and culture of the specimen [69]. Deciding upon the best type of sample for diagnosing 
VAP is controversial and at present no sampling procedure has proved meaningfully superior to the rest [70-72]. Culture samples should ideally be transferred to the Microbiology Department within 30 minutes of collection to avoid a delay in processing and bacterial overgrowth $[73,74]$. Storing LRT specimens refrigerated or frozen for 24 hours is an acceptable alternative when culturing cannot be performed immediately [75-77]. Despite this possibility, we would warn against this practice since any delay in receiving information will have devastating clinical consequences.

\section{Laboratory processing of samples upon arrival. Gram stain}

There is still much controversy over the value of the Gram stain for anticipating the microbiological diagnosis of VAP. The medical literature is replete with varying data on the sensitivity (57-95\%), specificity (48-87\%), positive predictive value (PPV) (47-78\%), negative predictive value (NPV) (69-96\%) and accuracy (60-88\%) of the Gram stain in the management of patients with VAP [78-82].

Some authors claim that a negative endotracheal aspirate (EA) Gram stain is of great negative predictive value for the diagnosis of VAP and may guide the decision to not initiate or to limit antibiotic treatment until culture results become available $[78,80,83,84]$. Our opinion is that immediate reporting to the responsible clinicians of the result of a Gram stain on LRT secretions obtained by tracheal aspiration may help guide early treatment. At our Microbiology Department, the diagnostic validity of the Gram technique on EA in patients with suspected VAP has been estimated at: sensitivity $91 \%$, specificity 61\%, PPV 50.5\%, NPV 94\%, test accuracy 70\%, positive likelihood ratio (PLR) 2.3, negative likelihood ratio (NLR) 0.14 , and a post-test probability of a negative result of $6 \%$ [85]. This means that a negative Gram stain makes it highly unlikely that a positive culture result will be obtained the next day.

As a complement to the Gram stain, quantifying the proportion of cells containing intracellular organisms has also been proposed as a rapid method for the diagnosis of VAP. A cut-off of $>1-2 \%$ of "infected" cells in bronchoalveolar lavage (BAL) specimens rendered a sensitivity of $79-93.6 \%$ and a specificity of $82-100 \%$ [86-88]. Thus, the detection of intracellular organisms in BAL specimens can be described as a rapid specific test with a high positive predictive value, and is recommended by the British Society of Antimicrobial Chemotherapy to guide initial therapy (grade A recommendation) [89]. In addition, this test does not seem to be affected by antibiotic therapy given up to 72 hours prior to sampling [90]. Along these lines, the European care bundle for the management of VAP recommends immediate reporting of Gram stain findings in respiratory secretions, including "infected" cells [91].
The guidelines of the Society for Healthcare and Epidemiology of America (SHEA) and the Infectious Diseases Society of America (IDSA) published in 2008 recommend a Gram stain directly on the sample and the quantitative culture of an EA or a BAL sample [92].

\section{Are there any other rapid direct methods that provide useful information before culture results become available?} Although it is widely accepted that the prognosis for a patient with VAP depends on the antibiotic susceptibility of the causative pathogen and on the time elapsed since its diagnosis and the first dose of effective antibiotic received [65,93], there is presently no rapid procedure other than those mentioned whose efficacy in the management of VAP has been reliably proven. In the specific field of VAP, there is a clear need to address new molecular techniques that can detect one or several microorganisms [94] or rapidly identify certain resistance mechanisms directly on clinical samples. We recently obtained excellent results for the rapid diagnosis of VAP due to methicillin-resistant or susceptible Staphylococcus aureus (MRSA, MSSA) by directly subjecting clinical samples to PCR (GeneXpert, Cepheid ${ }^{\oplus}$ Inc., Sunnyvale, CA) [95]. This simple procedure shows a high diagnostic efficiency and can shorten the time to adequate antibiotic treatment. These results have also been validated by other authors [96,97]. However, the GeneXpert kit has not yet received CE mark approval for this purpose. The ideal VAP molecular diagnostic assay should target various microorganisms and resistance genes, including S. aureus, Pseudomonas aeruginosa, Acinetobacter baumannii, a DNA sequence common to all Enterobacteriaceae, and the resistance genes $m e c A, b l a_{\mathrm{KPC}}, b l a_{\mathrm{IMP}} b l a_{\mathrm{VIM}}$ and bla ${ }_{\text {OXA }}$ [98].

\section{Rapid preliminary cultures and susceptibility testing (VAP E-test)}

Conventional processing of a secretion sample for microbiological investigation usually takes from 2 to 4 days. After inoculation and incubation for 24-48 hours, bacterial counts are performed and strains are isolated for pure culture. This is followed by pathogen identification and AST, which delays the results at least a further 24 hours. To this process, we would need to add the time of delays in transmitting information and in making therapeutic decisions.

In a study conducted at the Hospital Gregorio Marañón (Madrid, Spain), we compared the results of a direct E-test antibiogram for 6 antibiotic agents conducted on clinical LRT samples to those obtained by the standard AST. The E-test antimicrobial susceptibility procedure is a quantitative method for AST that consists of a plastic strip with a predefined gradient of antibiotic. The stable gradient provides inoculum tolerance where a 100 -fold variation in 
$\mathrm{cfu} / \mathrm{mL}$ has minimal effect on the minimum inhibitory concentration (MIC) of susceptible strains, and allows its application directly to clinical specimens [99]. The six antibiotics we used were oxacilin, cefepime, imipenem, piperacillin-tazobactam, amikacin and ciprofloxacin. Susceptibility data, obtained in 18 to 24 hours, were found to concur with those of the standard procedure at 48 to 72 hours in $98 \%$ of cases [100]. In a subsequent study, we confirmed the more effective and reduced use of antibiotics in VAP patients associated with the use of this quick procedure [101].

A new approach recently developed at our hospital is a modification of the direct E-test technique using a prototype chromogenic agar medium (Mueller-Hinton base) to generate both rapid antibiotic susceptibility and organism identification results $[102,103]$. In a preliminary investigation of 143 LRT samples, $92.7 \%$ of the isolates were rapidly identified in this medium after 18 hours and $100 \%$ after 24 hours of incubation. Full agreement with the standard procedure was observed in $94.9 \%$ (Cercenado et al., unpublished data). Although these data are preliminary, we consider the use of chromogenic agar medium for E-tests on LRT samples is an improvement over the use of conventional Mueller-Hinton agar.

\section{Other diagnostic markers of VAP}

The use of biomarkers such as CRP to more objectively and specifically diagnose VAP has also been assessed. Lisboa et al. used CRP as a diagnostic and prognostic marker, as well as to assess antibiotic treatment appropriateness [104]. These authors noted that the CRP coefficient (defined as the ratio between CRP levels on follow-up and CRP levels at baseline) decreased in patients receiving adequate treatment and that a coefficient of 0.8 at 96 hours post treatment onset was a good indicator of the appropriateness of antibiotic treatment (Se $77 \%$, Sp $87 \%$, area under the ROC curve $86 \%, 95 \%$ CI 75-96\%). Unfortunately, CRP is a nonspecific biomarker of inflammation and may also be elevated in the presence of pulmonary infiltrates of non-infectious cause [74].

Regarding PCT, it is not a good marker for the diagnosis of VAP [105]. However, in VAP, this marker has been described as prognostic with elevated levels indicating a more severe clinical course and sustained high levels during the first week of illness indicating a worse outcome [106]. Some studies have also correlated a drop in PCT with a favorable outcome $[107,108]$ and reduced antibiotic consumption [109], although in other studies, neither PCT threshold values nor their kinetics were able to predict VAP survival $[110,111]$.

Despite these discrepancies, PCT seems to be a good indicator of bacterial load in patients with VAP. Most importantly, a low level of PCT is thought to accurately reflect controlled bacterial infection [74].
Other proposed biomarkers are the soluble triggering receptor expressed on myeloid cells-1 (Strem-1) [112] and interleukin-1beta and interleukin-8 in BAL fluid [113]. Chastre et al. recommend that PCT and Strem-1 should only be used to complement standard microbiological diagnostic tests. However, knowledge of serum PCT and Strem-1 levels may prompt a change in treatment early in the course of VAP and such findings have been used to step-up treatment when levels remain high or to avoid long courses of antibiotics when the levels of these markers rapidly fall [114]. Whether PCT and/or Strem-1 guidance can reduce antibiotic use in such a setting is yet to be seen, but the strategy appears promising $[112,115]$.

\section{The rapid diagnosis of urinary tract infection}

The turnaround time for microbiological confirmation of a urinary tract infection (UTI) in a urine culture is not usually as critical as in life-threatening diseases like sepsis. Still, microbiological confirmation of a UTI takes 24-48 hours. In the meantime, patients are usually given empirical antibiotics, sometimes inappropriately.

\section{Rapid UTI screening methods. The Gram stain}

The usefulness of Gram staining of fresh uncentrifuged urine to detect significant bacteriuria was first demonstrated in 1968 [116], and it has since been used as a screening test for UTI [117-119]. The accuracy of Gram staining for the diagnosis of UTI has been reported in the literature as: sensitivity $82.2-97.9 \%$; specificity $66.0-$ 95.0\%; PPV 31.6-94.3\%, and NPV 95.2-99.5\%, varying with the different counts of microorganisms in the sample [118-122]. As with other rapid screening tests, accuracy is higher for greater bacterial counts.

The benefits of direct Gram staining of urine samples sent for culture are clear: it shortens the turnaround time for reporting negative culture results and guides empirical antibiotic treatment when microorganisms are seen. In addition, when compared to alternative rapid screening tests, the Gram stain has a higher accuracy $[119,123]$ and lower cost [122].

The use of the Gram stain has not been generalized because it needs more equipment and time than dipstick analysis, and is unlikely to replace dipstick testing across all health-care settings [123]. Skilled laboratory personnel are needed to correctly evaluate smears [124]. Yet, in laboratories where stained smears are part of the routine microbiological examination of urine samples, the time necessary to perform the stain and examine the slide under the microscope is relatively short [124].

MALDI-TOF mass spectrometry has been successfully used to rapidly identify culture-isolated microorganisms $[42,43]$ but has been little used directly on clinical 
samples except positive blood cultures and urine samples [48,125-128].

We recently assessed the capacity of subjecting urine samples to sequential Gram staining and MALDI-TOF MS to anticipate clinically useful information [129]. From May through June 2012, 1,000 random urine samples from patients with a suspected UTI were Gram stained, and those returning bacteria of a single morphotype were subjected to MALDI-TOF MS. This procedure was correlated with standard semiquantitative urine culture results and the outcomes recorded as: match (information anticipative of culture result), minor error (information partially anticipative of culture result), or major error (information incorrect and potentially leading to inappropriate antibiotic therapy decisions). Results were available in 1 hour. Information anticipative of culture results was provided in $83 \%$ of cases, information with minor errors in $13 \%$ and information with major errors in $4 \%$. For $96 \%$ of urine samples from patients with suspected UTI, the sequential procedure provided information that was consistent or showed minor errors. In future work, the clinical impacts of this rapid UTI diagnosis strategy need to be assessed in terms of factors such as a reduced time to appropriate empirical treatment or earlier withdrawal of unnecessary antibiotics.

\section{Anticipation of antibiotic susceptibility with direct testing} The practice of performing direct AST of urine specimens has the advantage of next-day reporting of antimicrobial susceptibilities. Direct AST of urine samples has proved to be as effective as standard methods, providing results 24 hours in advance with similar costs [130]. However, this method is criticized because the inoculum is not standardized and because sometimes a mixture of microorganisms can be found in the sample. Nevertheless, it has been used for many years with excellent results [131-136] and correlates well with reference methods. The fact that this method can confirm the appropriate antibiotic treatment in only 24 hours translates to the reduced use of wide-spectrum antibiotics with the consequence of diminishing antibiotic resistance.

\section{Rapid diagnosis of skin and soft tissue infections}

According to the IDSA 2013 guide to the diagnosis of infectious diseases [137], cultures are not indicated for uncomplicated common forms of skin and soft tissue infections (SSTIs) (e.g., cellulitis, subcutaneous abscesses) treated in the outpatient setting. Whether cultures are beneficial for managing cellulitis in the hospitalized patient is uncertain and the sensitivity of blood cultures in this setting is low. Cultures are however recommended for the patient who requires operative incision and drainage because of the risk of deep structure and underlying tissue involvement [138]. The IDSA guide includes recommendations for sampling and processing specimens for a microbiological diagnosis of the most frequent SSTIs. Basically, the quality of the sample and the number of potential pathogens to be considered is first established in a Gram stain, and this is followed by a conventional culture procedure. These still traditional procedures are not rapid.

The recent availability of a rapid-detection assay to identify MRSA from wound specimens allows for betterinformed therapeutic decisions. The Xpert MRSA/SA skin and soft tissue infection assay (GeneXpert, Cepheid ${ }^{\circ}$ Inc., Sunnyvale, CA) is approved for rapid detection (within $1 \mathrm{~h}$ ) of MRSA and MSSA in wounds. In a multicenter evaluation that included a total of 114 wound specimens, the MRSA/SA SSTI assay showed a Se of $97 \%$, a Sp of $96 \%$, a PPV of $92 \%$ and a NPV of $99 \%$ for MRSA detection; similar percentages were noted for MSSA [139]. Overall agreement between the assay and standard culture was $96.5 \%$.

The GeneXpert kit directly applied to synovial fluid and tissue specimens (e.g., bone, muscle, fascia, etc.) has also proved useful for the diagnosis of osteoarticular and chronic prosthetic joint infections due to staphylococci $[140,141]$, though it has not yet received CE mark approval for this purpose.

The rapid identification and differentiation of MRSA in a wound specimen allows clinicians to more rapidly initiate appropriate antimicrobial therapy.

The steps recommended for the early diagnosis of a SSTI by Streptococcus pyogenes are: direct Gram staining of skin biopsies, tissues, fascia, muscle, purulent exudate or joint aspirates and the rapid detection of capsule and protein antigens in skin and/or tissues using available kits that show a Se of $60 \%$ to $91 \%$ and a Sp of $85 \%$ to 98\% [142-144].

\section{Other rapid microbiological tests that may provide useful information in ICU patients}

Besides the tests already mentioned, other diagnostic tests used in Microbiology can expedite the diagnosis of infection in these patients.

Those most often used in clinical practice, which also show adequate diagnostic performance, are the detection of the antigens of Streptococcus pneumoniae [145] and Legionella pneumophila serogroup 1 in urine [146] for patients with pneumonia; the detection of some viruses such as influenza and other respiratory viruses, or enterovirus and other central nervous system viruses [147]; and the detection of Mycobacterium tuberculosis, which in some cases is accompanied by the identification of resistance genes [148]. The detection of respiratory viral agents includes single or multiple pathogens (multiplex panels), which is highly convenient since most of these agents cause similar symptoms. 


\section{Conclusions}

Much progress has been recently made in the rapid etiologic diagnosis of infectious diseases. Some of the new approaches available are even able to detect antimicrobial resistances and this allows for treatment optimization, especially in the most vulnerable patients such as those admitted to the ICU. Current microbiology has shortened turnaround times in the treatment of many types of infection, such as sepsis, pneumonia, urinary tract infections, skin and soft tissue infections, viral infections or tuberculosis. Molecular techniques still have issues that need to be dealt with such as their limits of detection and sensitivity for certain samples and certain situations, their correlation with adequate diagnostic gold standards, their clinical validation and the correct interpretation of results, and the risk of contamination. Improvements are also needed in terms of widening the spectrum of pathogens and resistance mechanisms that may be identified or the sample types these procedures can be used on. Despite these limitations, the future of the field of molecular techniques for the rapid diagnosis of infections is highly promising.

\begin{abstract}
Abbreviations
AST: Antibiotic susceptibility testing; AUC: Area under the curve; BAL: Bronchoalveolar lavage; BCB: Blood culture bottles; BSI: Bloodstream infection; CA-UTI: Catheter associated urinary tract infection; CE: Conformité Européenne, meaning "European Conformity". It is a mandatory conformity marking for certain products sold within the European Economic Area (EEA) since 1985; cfu/mL: colony forming units/millilitre; CR: Catheter-related; CR-BSI: Intravascular catheter-related bloodstream infection; CRP: C-reactive protein; CVC: Central venous catheter; DTTP: Differential time to positivity; EA: Endotracheal aspirate; HAP: Hospital acquired pneumonia; ICU: Intensive care unit; LRT: Lower respiratory tract; MRSA: Methicillin-resistant Staphylococcus aureus; MSSA: Methicillin-susceptible Staphylococcus aureus; NAT: Nucleic acid testing; NLR: Negative likelihood ratio; NPV: Negative predictive value; PBS: Phosphate-buffered saline; PCR: Polymerase chain reaction; PCT: Procalcitonin; PLR: Positive likelihood ratio; PPV: Positive predictive value; ROC curve: Receiver operating characteristic curve; Se: Sensitivity; Sp: Specificity; SSTI: Skin and soft tissue infection; STREM-1: Soluble triggering receptor expressed on myeloid cells-1; UTI: Urinary tract infection; VAP: Ventilator associated pneumonia.
\end{abstract}

\section{Competing interests}

The authors declare that they have no competing interests.

\section{Authors' contributions}

$E B$ and $A B$ took primary responsibility for the literature search, drafted the manuscript, wrote the manuscript, critically revised the manuscript, read and approved the final version.

\section{Acknowledgements}

The authors thank the Fundación Rafael del Pino for its contribution to research in the field of nosocomial infections and Ana Burton for editorial assistance.

\section{Financial support}

This study was funded in part by the Programa de Centros de Investigación Biomédica en Red (CIBER) de Enfermedades Respiratorias CB06/06/0058.

\section{Author details}

${ }^{1}$ Clinical Microbiology and Infectious Diseases Department, Hospital General Universitario Gregorio Marañón, Doctor Esquerdo 46, 28007 Madrid, Spain. ${ }^{2}$ Instituto de Investigación Sanitaria Gregorio Marañón, Madrid, Spain. ${ }^{3}$ Medicine Department, School of Medicine, Universidad Complutense de Madrid, Madrid, Spain. ${ }^{4} \mathrm{CIBER}$ de Enfermedades Respiratorias (CIBERES CB06) 06/0058), Madrid, Spain.
Received: 8 April 2014 Accepted: 28 October 2014

Published online: 28 November 2014

\section{References}

1. Burgmann H, Hiesmayr JM, Savey A, Bauer P, Metnitz B, Metnitz PG: Impact of nosocomial infections on clinical outcome and resource consumption in critically ill patients. Intensive Care Med 2010, 36:1597-1601.

2. Cohen ER, Feinglass J, Barsuk JH, Barnard C, O'Donnell A, McGaghie WC, Wayne DB: Cost savings from reduced catheter-related bloodstream infection after simulation-based education for residents in a medical intensive care unit. Simul Healthc 2010, 5:98-102.

3. Zarb P, Coignard B, Griskeviciene J, Muller A, Vankerckhoven V, Weist K, Goossens M, Vaerenberg S, Hopkins S, Catry B, Monnet D, Goossens H, Suetens C: The European Centre for Disease Prevention and Control (ECDC) pilot point prevalence survey of healthcare-associated infections and antimicrobial use. Euro Surveill 2012, 17:20316.

4. Olaechea PM, Palomar M, Alvarez-Lerma F, Otal JJ, Insausti J, Lopez-Pueyo MJ: Morbidity and mortality associated with primary and catheterrelated bloodstream infections in critically ill patients. Rev Esp Quimioter 2013, 26:21-29.

5. Hidron Al, Edwards JR, Patel J, Horan TC, Sievert DM, Pollock DA, Fridkin SK NHSN annual update: antimicrobial-resistant pathogens associated with healthcare-associated infections: annual summary of data reported to the National Healthcare Safety Network at the Centers for Disease Control and Prevention, 2006-2007. Infect Control Hosp Epidemiol 2008, 29:996-1011.

6. Brusselaers $N$, Vogelaers D, Blot $\mathrm{S}$ : The rising problem of antimicrobial resistance in the intensive care unit. Ann Intensive Care 2011, 1:47.

7. Ibrahim EH, Sherman G, Ward S, Fraser VJ, Kollef MH: The influence of inadequate antimicrobial treatment of bloodstream infections on patient outcomes in the ICU setting. Chest 2000, 118:146-155.

8. Muscedere JG, Shorr AF, Jiang X, Day A, Heyland DK: The adequacy of timely empiric antibiotic therapy for ventilator-associated pneumonia: an important determinant of outcome. J Crit Care 2012, 27:322. e327-314

9. Palmer HR, Palavecino EL, Johnson JW, Ohl CA, Williamson JC: Clinical and microbiological implications of time-to-positivity of blood cultures in patients with Gram-negative bacilli bacteremia. Eur I Clin Microbiol Infect Dis 2013, 32:955-959.

10. Raad I, Hanna H, Maki D: Intravascular catheter-related infections: advances in diagnosis, prevention, and management. Lancet Infect Dis 2007, 7:645-657.

11. Rello J, Coll P, Prats G: Evaluation of culture techniques for diagnosis of catheter-related sepsis in critically ill patients. Eur J Clin Microbiol Infect Dis 1992, 11:1192-1193.

12. Benezra D, Kiehn TE, Gold JW, Brown AE, Turnbull AD, Armstrong D: Prospective study of infections in indwelling central venous catheters using quantitative blood cultures. Am J Med 1988, 85:495-498.

13. Rijnders BJ, Peetermans WE, Verwaest C, Wilmer A, Van Wijngaerden E: Watchful waiting versus immediate catheter removal in ICU patients with suspected catheter-related infection: a randomized trial. Intensive Care Med 2004, 30:1073-1080

14. Fortun J, Grill F, Martin-Davila P, Blazquez J, Tato M, Sanchez-Corral J, Garcia-San Miguel L, Moreno S: Treatment of long-term intravascular catheter-related bacteraemia with antibiotic-lock therapy. J Antimicrob Chemother 2006, 58:816-821.

15. Safdar N, Fine JP, Maki DG: Meta-analysis: methods for diagnosing intravascular device-related bloodstream infection. Ann Intern Med 2005, 142:451-466.

16. Cercenado E, Ena J, Rodriguez-Creixems M, Romero I, Bouza E: A conservative procedure for the diagnosis of catheter-related infections. Arch Intern Med 1990, 150:1417-1420.

17. Fortun J, Perez-Molina JA, Asensio A, Calderon C, Casado JL, Mir N, Moreno A, Guerrero A: Semiquantitative culture of subcutaneous segment for conservative diagnosis of intravascular catheter-related infection. JPEN J Parenter Enteral Nutr 2000, 24:210-214.

18. Bouza E, Munoz P, Burillo A, Lopez-Rodriguez J, Fernandez-Perez C, Perez $\mathrm{MJ}$, Rincon C: The challenge of anticipating catheter tip colonization in major heart surgery patients in the intensive care unit: are surface cultures useful? Crit Care Med 2005, 33:1953-1960

19. Blot F: Diagnosis of catheter-related infections. In Catheter-Related Infections. Edited by Seifert H, Jansen B, Farr B. New York: Marcel Dekker; 2005:37-76 
20. Guembe M, Rodriguez-Creixems M, Sanchez-Carrillo C, Perez-Parra A, MartinRabadan P, Bouza E: How many lumens should be cultured in the conservative diagnosis of catheter-related bloodstream infections? Clin Infect Dis 2010, 50:1575-1579.

21. Hamilton DJ, Amos D, Schwartz RW, Dent CM, Counts GW: Effect of delay in processing on lysis-centrifugation blood culture results from marrow transplant patients. J Clin Microbiol 1989, 27:1588-1593.

22. Raad I, Hanna HA, Alakech B, Chatzinikolaou I, Johnson MM, Tarrand J: Differential time to positivity: a useful method for diagnosing catheterrelated bloodstream infections. Ann Intern Med 2004, 140:18-25.

23. Sabatier C, Garcia X, Ferrer R, Duarte M, Colomina M, Alcaraz D, Fontanals D, Valles J: Blood culture differential time to positivity enables safe catheter retention in suspected catheter-related bloodstream infection: a randomized controlled trial. Med Intensiva 2014, in press.

24. Blot F, Nitenberg G, Chachaty E, Raynard B, Germann N, Antoun S, Laplanche A, Brun-Buisson C, Tancrede C: Diagnosis of catheter-related bacteraemia: a prospective comparison of the time to positivity of hubblood versus peripheral-blood cultures. Lancet 1999, 354:1071-1077.

25. Abdelkefi A, Achour W, Ben Othman T, Torjman L, Ladeb S, Lakhal A, Hsairi $M$, Kammoun L, Ben Hassen A, Ben Abdeladhim A: Difference in time to positivity is useful for the diagnosis of catheter-related bloodstream infection in hematopoietic stem cell transplant recipients. Bone Marrow Transplant 2005, 35:397-401.

26. Kaasch AJ, Rieg S, Hellmich M, Kern WW, Seifert H: Differential time to positivity is not predictive for central line-related Staphylococcus aureus bloodstream infection in routine clinical care. J Infect 2014, 68:58-61.

27. Schwetz I, Hinrichs G, Reisinger EC, Krejs GJ, Olschewski H, Krause R: Delayed processing of blood samples influences time to positivity of blood cultures and results of Gram stain-acridine orange leukocyte Cytospin test. J Clin Microbiol 2007, 45:2691-2694.

28. Kaasch AJ, Rieg S, Hellmich M, Kern WW, Seifert H: Reply to Krause et al. J Infect 2014, 69:294-295.

29. Bouza E, Alcala L, Munoz P, Martin-Rabadan P, Guembe M, Rodriguez-Creixems M: Can microbiologists help to assess catheter involvement in candidaemic patients before removal? Clin Microbiol Infect 2013, 19:E129-E135.

30. Leon M, Garcia M, Herranz MA, Gonzalez V, Martinez A, Castillo F, Andres E, Leon C, Huet J: Diagnostic value of Gram staining of peri-catheter skin and the connection in the prediction of intravascular-catheter-related bacteremia. Enferm Infecc Microbiol Clin 1998, 16:214-218.

31. Bouza E, Alvarado N, Alcala L, Perez MJ, Rincon C, Munoz P: A randomized and prospective study of 3 procedures for the diagnosis of catheterrelated bloodstream infection without catheter withdrawal. Clin Infect Dis 2007, 44:820-826.

32. Castellanos-Ortega A, Suberviola B, Garcia-Astudillo LA, Holanda MS, Ortiz F, Llorca J, Delgado-Rodriguez M: Impact of the Surviving Sepsis Campaign protocols on hospital length of stay and mortality in septic shock patients: results of a three-year follow-up quasi-experimental study. Crit Care Med 2010, 38:1036-1043

33. Fenollar F, Raoult D: Molecular diagnosis of bloodstream infections caused by non-cultivable bacteria. Int J Antimicrob Agents 2007, 30(Suppl 1):S7-S15.

34. Afshari A, Schrenzel J, leven M, Harbarth S: Bench-to-bedside review: rapid molecular diagnostics for bloodstream infection - a new frontier? Crit Care $2012,16: 222$

35. Liesenfeld O, Lehman L, Hunfeld KP, Kost G: Molecular diagnosis of sepsis: New aspects and recent developments. Eur J Microbiol Immunol (Bp) 2014, 4:1-25.

36. Murray PR, Masur H: Current approaches to the diagnosis of bacterial and fungal bloodstream infections in the intensive care unit. Crit Care Med 2012, 40:3277-3282

37. Chang SS, Hsieh WH, Liu TS, Lee SH, Wang CH, Chou HC, Yeo YH, Tseng CP, Lee CC: Multiplex PCR system for rapid detection of pathogens in patients with presumed sepsis - a systemic review and meta-analysis. PLoS One 2013, 8:e62323.

38. Wallet F, Loiez C, Herwegh S, Courcol RJ: Usefulness of real-time PCR for the diagnosis of sepsis in ICU-acquired infections. Infect Disord Drug Targets 2011, 11:348-353.

39. Schrenzel J: PCR for the diagnosis of sepsis: hope or hype? Crit Care 2011, 15:111.

40. Dierkes C, Ehrenstein B, Siebig S, Linde HJ, Reischl U, Salzberger B: Clinical impact of a commercially available multiplex PCR system for rapid detection of pathogens in patients with presumed sepsis. BMC Infect Dis 2009, 9:126.
41. Fernandez-Cruz A, Marin M, Kestler M, Alcala L, Rodriguez-Creixems M, Bouza E: The value of combining blood culture and SeptiFast data for predicting complicated bloodstream infections caused by Gram-positive bacteria or Candida species. J Clin Microbiol 2013, 51:1130-1136.

42. Lehmann LE, Herpichboehm B, Kost GJ, Kollef MH, Stuber F: Cost and mortality prediction using polymerase chain reaction pathogen detection in sepsis: evidence from three observational trials. Crit Care 2010, 14:R186.

43. Ho YP, Reddy PM: Advances in mass spectrometry for the identification of pathogens. Mass Spectrom Rev 2011, 30:1203-1224.

44. Cherkaoui A, Hibbs J, Emonet S, Tangomo M, Girard M, Francois P, Schrenzel J: Comparison of two matrix-assisted laser desorption ionization-time of flight mass spectrometry methods with conventional phenotypic identification for routine identification of bacteria to the species level. J Clin Microbiol 2010, 48:1169-1175.

45. Spanu T, Posteraro B, Fiori B, D'Inzeo T, Campoli S, Ruggeri A, Tumbarello M, Canu G, Trecarichi EM, Parisi G, Tronci M, Sanguinetti M, Fadda G: Direct maldi-tof mass spectrometry assay of blood culture broths for rapid identification of Candida species causing bloodstream infections: an observational study in two large microbiology laboratories. J Clin Microbiol 2012, 50:176-179.

46. Juiz PM, Almela M, Melcion C, Campo I, Esteban C, Pitart C, Marco F, Vila J: A comparative study of two different methods of sample preparation for positive blood cultures for the rapid identification of bacteria using MALDI-TOF MS. Eur J Clin Microbiol Infect Dis 2012, 31:1353-1358.

47. Leli C, Cenci E, Cardaccia A, Moretti A, D'Alo F, Pagliochini R, Barcaccia M, Farinelli S, Vento S, Bistoni F, Mencacci A: Rapid identification of bacterial and fungal pathogens from positive blood cultures by MALDI-TOF MS. Int J Med Microbiol 2013, 303:205-209.

48. Rodriguez-Sanchez B, Sanchez-Carrillo C, Ruiz A, Marin M, Cercenado E, Rodriguez-Creixems M, Bouza E: Direct identification of pathogens from positive blood cultures using matrix-assisted laser desorption-ionization time-of-flight mass spectrometry. Clin Microbiol Infec 2013. doi:10.1111/ 1469-0691.12455

49. Vlek AL, Bonten MJ, Boel CH: Direct matrix-assisted laser desorption ionization time-of-flight mass spectrometry improves appropriateness of antibiotic treatment of bacteremia. PLoS One 2012, 7:e32589.

50. Reinhart K, Bauer M, Riedemann NC, Hartog CS: New approaches to sepsis: molecular diagnostics and biomarkers. Clin Microbiol Rev 2012, 25:609-634.

51. Pierrakos C, Vincent JL: Sepsis biomarkers: a review. Crit Care 2010, 14:R15.

52. Povoa P, Coelho L, Almeida E, Fernandes A, Mealha R, Moreira P, Sabino H: C-reactive protein as a marker of infection in critically ill patients. Clin Microbiol Infect 2005, 11:101-108.

53. Povoa P, Coelho L, Almeida E, Fernandes A, Mealha R, Moreira P, Sabino H: Early identification of intensive care unit-acquired infections with daily monitoring of C-reactive protein: a prospective observational study. Crit Care 2006, 10:R63.

54. Lobo SM, Lobo FR, Bota DP, Lopes-Ferreira F, Soliman HM, Melot C, Vincent $\mathrm{J}$ : C-reactive protein levels correlate with mortality and organ failure in critically ill patients. Chest 2003, 123:2043-2049.

55. Garnacho-Montero J, Huici-Moreno MJ, Gutierrez-Pizarraya A, Lopez I, Marquez-Vacaro JA, Macher H, Guerrero JM, Puppo-Moreno A: Prognostic and diagnostic value of eosinopenia, C-reactive protein, procalcitonin, and circulating cell-free DNA in critically ill patients admitted with suspicion of sepsis. Crit Care 2014, 18:R116.

56. Giamarellos-Bourboulis EJ, Tsangaris I, Kanni T, Mouktaroudi M, Pantelidou I, Adamis G, Atmatzidis S, Chrisofos M, Evangelopoulou V, Frantzeskaki F, Giannopoulos P, Giannikopoulos G, Gialvalis D, Gourgoulis GM, Kotzampassi K, Katsifa K, Kofinas G, Kontopidou F, Koratzanis G, Koulouras V, Koutsikou A, Koupetori M, Kritselis I, Leonidou L, Mega A, Mylona V, Nikolaou H, Orfanos S, Panagopoulos P, Paramythiotou E, et al: Procalcitonin as an early indicator of outcome in sepsis: a prospective observational study. $J$ Hosp Infect 2011, 77:58-63.

57. Karlsson S, Heikkinen M, Pettila V, Alila S, Vaisanen S, Pulkki K, Kolho E, Ruokonen E: Predictive value of procalcitonin decrease in patients with severe sepsis: a prospective observational study. Crit Care 2010, 14:R205

58. Dellinger RP, Levy MM, Rhodes A, Annane D, Gerlach H, Opal SM, Sevransky JE, Sprung CL, Douglas IS, Jaeschke R, Osborn TM, Nunnally ME, Townsend SR, Reinhart K, Kleinpell RM, Angus DC, Deutschman CS, Machado FR, Rubenfeld GD, Webb SA, Beale RJ, Vincent JL, Moreno R: Surviving sepsis campaign: international guidelines for management of severe sepsis and septic shock: 2012. Crit Care Med 2013, 41:580-637. 
59. Rello J: Bench-to-bedside review: Therapeutic options and issues in the management of ventilator-associated bacterial pneumonia. Crit Care 2005, 9:259-265

60. Kollef $\mathrm{MH}$ : What is ventilator-associated pneumonia and why is it important? Respir Care 2005, 50:714-724

61. Chastre J: Conference summary: ventilator-associated pneumonia. Respir Care 2005, 50:975-983

62. Muscedere JG, Martin CM, Heyland DK: The impact of ventilator-associated pneumonia on the Canadian health care system. J Crit Care 2008, 23:5-10.

63. Hortal J, Munoz P, Cuerpo G, Litvan H, Rosseel PM, Bouza E: Ventilatorassociated pneumonia in patients undergoing major heart surgery: an incidence study in Europe. Crit Care 2009, 13:R80.

64. Iregui M, Ward S, Sherman G, Fraser VJ, Kollef MH: Clinical importance of delays in the initiation of appropriate antibiotic treatment for ventilatorassociated pneumonia. Chest 2002, 122:262-268.

65. Kuti EL, Patel AA, Coleman Cl: Impact of inappropriate antibiotic therapy on mortality in patients with ventilator-associated pneumonia and blood stream infection: a meta-analysis. J Crit Care 2008, 23:91-100

66. Blot S: Limiting the attributable mortality of nosocomial infection and multidrug resistance in intensive care units. Clin Microbiol Infect 2008, 14(1):5-13.

67. Bogaerts $\mathrm{P}$, Hamels $\mathrm{S}$, de Mendonca R, Huang TD, Roisin S, Remacle J, Markine-Goriaynoff N, de Longueville F, Pluster W, Denis O, Glupczynski Y: Analytical validation of a novel high multiplexing real-time PCR array for the identification of key pathogens causative of bacterial ventilatorassociated pneumonia and their associated resistance genes. J Antimicrob Chemother 2013, 68:340-347.

68. Hogardt M, Trebesius K, Geiger AM, Hornef M, Rosenecker J, Heesemann J: Specific and rapid detection by fluorescent in situ hybridization of bacteria in clinical samples obtained from cystic fibrosis patients. J Clin Microbiol 2000, 38:818-825.

69. American Thoracic Society, Infectious Diseases Society of America: Guidelines for the management of adults with hospital-acquired ventilator-associated, and healthcare-associated pneumonia. Am J Respir Crit Care Med 2005, 171:388-416.

70. de Jaeger A, Litalien C, Lacroix J, Guertin MC, Infante-Rivard C: Protected specimen brush or bronchoalveolar lavage to diagnose bacterial nosocomial pneumonia in ventilated adults: a meta-analysis. Crit Care Med 1999, 27:2548-2560

71. Torres A, El-Ebiary M: Bronchoscopic BAL in the diagnosis of ventilatorassociated pneumonia. Chest 2000, 117(4 Suppl 2):198S-202S.

72. Berton DC, Kalil AC, Teixeira PJZ: Quantitative versus qualitative cultures of respiratory secretions for clinical outcomes in patients with ventilatorassociated pneumonia. Cochrane Database of Systematic Reviews 2014, (10):CD006482. DOI:10.1002/14651858.CD006482.pub4.

73. Baselski VS, El-Torky M, Coalson JJ, Griffin JP: The standardization of criteria for processing and interpreting laboratory specimens in patients with suspected ventilator- associated pneumonia. Chest 1992 102(5 Suppl 1):571S-579S.

74. Wunderink RG: Surrogate markers and microbiologic end points. Clin Infect Dis 2010, 51(Suppl 1):S126-S130

75. Georges H, Santre C, Leroy O, Roussel-Delvallez M, Caillaux M, Beuscart C, Guery B, Vandenbussche C, Beaucaire G: Reliability of quantitative cultures of protected specimen brush after freezing. Am J Respir Crit Care Med 1996, 153:855-857.

76. de Lassence A, Joly-Guillou ML, Martin-Lefevre L, Le Miere E, Lasry S, Morelot C, Coste F, Dreyfuss D: Accuracy of delayed cultures of plugged telescoping catheter samples for diagnosing bacterial pneumonia. Crit Care Med 2001 29:1311-1317.

77. de Lassence A, Joly-Guillou ML, Salah A, Martin-Lefevre L, Hidri N, Ricard JD, Bouvry D, de Castro N, Dreyfuss D: Accuracy of delayed ( 24 hours) processing of bronchoalveolar lavage for diagnosing bacterial pneumonia. Crit Care Med 2004, 32:680-685.

78. Maillet JM, Fitoussi F, Penaud D, Dennewald G, Brodaty D: Concordance of antibiotic prophylaxis, direct Gram staining and protected brush specimen culture results for postoperative patients with suspected pneumonia. Eur J Anaesthesiol 2006, 23:563-567.

79. Davis KA, Eckert MJ, Reed RL 2nd, Esposito TJ, Santaniello JM, Poulakidas S, Luchette FA: Ventilator-associated pneumonia in injured patients: do you trust your Gram's stain? J Trauma 2005, 58:462-466.

80. Blot F, Raynard B, Chachaty E, Tancrede C, Antoun S, Nitenberg G: Value of gram stain examination of lower respiratory tract secretions for early diagnosis of nosocomial pneumonia. Am J Respir Crit Care Med 2000, 162:1731-1737.

81. Croce MA, Fabian TC, Waddle-Smith L, Melton SM, Minard G, Kudsk KA, Pritchard FE: Utility of Gram's stain and efficacy of quantitative cultures for posttraumatic pneumonia: a prospective study. Ann Surg 1998 227:743-751.

82. Prekates A, Nanas S, Argyropoulou A, Margariti G, Kyprianou T, Papagalos E, Paniara O, Roussos C: The diagnostic value of gram stain of bronchoalveolar lavage samples in patients with suspected ventilatorassociated pneumonia. Scand J Infect Dis 1998, 30:43-47.

83. Marquette $\mathrm{CH}$, Wallet F, Neviere R, Copin MC, Saulnier F, Drault JN, Mehdaoui $H$, Mathieu D, Ramon P: Diagnostic value of direct examination of the protected specimen brush in ventilator-associated pneumonia. Eur Respir J 1994, 7:105-113.

84. dos Santos RP, Deutschendorf C, Nagel F, Konkewicz L, Lisboa T: Antimicrobial stewardship lessons: know when to say no to vancomycin. Clin Infect Dis 2013, 56:616-617.

85. Torres M, Radice C, Sánchez C, Martín-Rabadán P, Muñoz P, Bouza E: [Performance of Gram stain in lower respiratory tract (LRT) samples in ventilator-associated pneumonia (VAP): a prospective study]. (Abstract). In: XII Congress of the Spanish Society of Infectious Diseases and Clinical Microbiology. Valencia, Spain; 2006.

86. Sirvent JM, Vidaur L, Gonzalez S, Castro P, de Batlle J, Castro A, Bonet A: Microscopic examination of intracellular organisms in protected bronchoalveolar mini-lavage fluid for the diagnosis of ventilatorassociated pneumonia. Chest 2003, 123:518-523.

87. Timsit JF, Cheval C, Gachot B, Bruneel F, Wolff M, Carlet J, Regnier B: Usefulness of a strategy based on bronchoscopy with direct examination of bronchoalveolar lavage fluid in the initial antibiotic therapy of suspected ventilator-associated pneumonia. Intensive Care Med 2001, 27:640-647.

88. Mentec H, May-Michelangeli L, Rabbat A, Varon E, Le Turdu F, Bleichner G: Blind and bronchoscopic sampling methods in suspected ventilatorassociated pneumonia. A multicentre prospective study. Intensive Care Med 2004, 30:1319-1326.

89. Masterton RG, Galloway A, French G, Street M, Armstrong J, Brown E, Cleverley J, Dilworth P, Fry C, Gascoigne AD, Knox A, Nathwani D, Spencer $R$, Wilcox M: Guidelines for the management of hospital-acquired pneumonia in the UK: report of the working party on hospital-acquired pneumonia of the British Society for Antimicrobial Chemotherapy. J Antimicrob Chemother 2008, 62:5-34.

90. Linssen CF, Jacobs JA, Schouten JS, van Mook WN, Ramsay G, Drent M: Influence of antibiotic therapy on the cytological diagnosis of ventilatorassociated pneumonia. Intensive Care Med 2008, 34:865-872.

91. Rello J, Chastre J, Cornaglia G, Masterton R: A European care bundle for management of ventilator-associated pneumonia. J Crit Care 2011, 26:3-10.

92. Coffin SE, Klompas M, Classen D, Arias KM, Podgorny K, Anderson DJ, Burstin H, Calfee DP, Dubberke ER, Fraser V, Gerding DN, Griffin FA, Gross P, Kaye KS, Lo E, Marschall J, Mermel LA, Nicolle L, Pegues DA, Perl TM, Saint S, Salgado CD, Weinstein RA, Wise R, Yokoe DS: Strategies to prevent ventilator-associated pneumonia in acute care hospitals. Infect Control Hosp Epidemiol 2008, 29(Suppl 1):S31-S40.

93. Vidaur L, Planas K, Sierra R, Dimopoulos G, Ramirez A, Lisboa T, Rello J: Ventilator-associated pneumonia: impact of organisms on clinical resolution and medical resources utilization. Chest 2008, 133:625-632.

94. Bahrani-Mougeot FK, Paster BJ, Coleman S, Barbuto S, Brennan MT, Noll J, Kennedy T, Fox PC, Lockhart PB: Molecular analysis of oral and respiratory bacterial species associated with ventilator-associated pneumonia. J Clin Microbiol 2007, 45:1588-1593.

95. Cercenado E, Marin M, Burillo A, Martin-Rabadan P, Rivera M, Bouza E: Rapid detection of Staphylococcus aureus in lower respiratory tract secretions from patients with suspected ventilator-associated pneumonia: evaluation of the Cepheid Xpert MRSA/SA SSTI assay. J Clin Microbiol 2012, 50:4095-4097.

96. Leone M, Malavieille F, Papazian L, Meyssignac B, Cassir N, Textoris J, Antonini F, La Scola B, Martin C, Allaouchiche B, Hraiech S: Routine use of Staphylococcus aureus rapid diagnostic test in patients with suspected ventilator-associated pneumonia. Crit Care 2013, 17:R170.

97. Oh AC, Lee JK, Lee HN, Hong YJ, Chang YH, Hong SI, Kim DH: Clinical utility of the Xpert MRSA assay for early detection of methicillin-resistant Staphylococcus aureus. Mol Med Rep 2013, 7:11-15. 
98. Tenover FC: Developing molecular amplification methods for rapid diagnosis of respiratory tract infections caused by bacterial pathogens. Clin Infect Dis 2011, 52(Suppl 4):S338-S345.

99. Bolmström A, Arvidson S, Ericsson M, Karlsson A: A novel technique for direct quantification of antimicrobial susceptibility of microorganisms. In 28th Interscience Conference on Antimicrobial Agents and Chemotherapy; Los Angeles, (US); 1988.

100. Cercenado E, Rico MV, Vicente T, Bouza E: Rapid Antimicrobial Susceptibility Testing in Patients with Ventilator-Associated Pneumonia: Direct E-Test on Respiratory Samples. (Abstract: D-51). In 42nd Interscience Conference on Antimicrobial Agents and Chemotherapy: 2002; San Diego (US); 2002

101. Bouza E, Torres MV, Radice C, Cercenado E, de Diego R, Sanchez-Carrillo C, Munoz P: Direct E-test (AB Biodisk) of respiratory samples improves antimicrobial use in ventilator-associated pneumonia. Clin Infect Dis 2007, 44(3):382-387

102. Muñoz P, Cercenado E, Giannella M, Bouza E: Rapid detection of microorganism resistance in patients with ventilator-associated pneumonia. Clin Pulm Med 2009, 16(6):302-308.

103. Cercenado E, Marin M, Insa R, Martin-Rabadan P, Rivera M, Bouza E: Evaluation of direct E-test on lower respiratory tract samples using a chromogenic agar medium: a rapid procedure for antimicrobial susceptibility testing. (Abstract P822). In 19th Congress of the ESCMID: 2009. Finland: Helsinki; 2009.

104. Lisboa T, Seligman R, Diaz E, Rodriguez A, Teixeira PJ, Rello J: C-reactive protein correlates with bacterial load and appropriate antibiotic therapy in suspected ventilator-associated pneumonia. Crit Care Med 2008, 36:166-171.

105. Jung B, Embriaco N, Roux F, Forel JM, Demory D, Allardet-Servent J, Jaber S, La Scola B, Papazian L: Microbiogical data, but not procalcitonin improve the accuracy of the clinical pulmonary infection score. Intensive Care Med 2010, 36:790-798.

106. Luyt CE, Guerin V, Combes A, Trouillet JL, Ayed SB, Bernard M, Gibert C, Chastre J: Procalcitonin kinetics as a prognostic marker of ventilatorassociated pneumonia. Am J Respir Crit Care Med 2005, 171:48-53.

107. Seligman R, Meisner M, Lisboa TC, Hertz FT, Filippin TB, Fachel JM, Teixeira $\mathrm{PJ}$ : Decreases in procalcitonin and $\mathrm{C}$-reactive protein are strong predictors of survival in ventilator-associated pneumonia. Crit Care 2006 10:R125.

108. Su LX, Meng K, Zhang X, Wang HJ, Yan P, Jia YH, Feng D, Xie LX: Diagnosing ventilator-associated pneumonia in critically ill patients with sepsis. Am J Crit Care 2012, 21:e110-e119.

109. Nobre V, Harbarth S, Graf JD, Rohner P, Pugin J: Use of procalcitonin to shorten antibiotic treatment duration in septic patients: a randomized trial. Am J Respir Crit Care Med 2008, 177:498-505.

110. Linssen CF, Bekers $O$, Drent $M$, Jacobs JA: C-reactive protein and procalcitonin concentrations in bronchoalveolar lavage fluid as a predictor of ventilator- associated pneumonia. Ann Clin Biochem 2008, 45:293-298

111. Hillas G, Vassilakopoulos T, Plantza P, Rasidakis A, Bakakos P: C-reactive protein and procalcitonin as predictors of survival and septic shock in ventilator-associated pneumonia. Eur Respir J 2010, 35:805-811.

112. Chastre J, Luyt CE, Trouillet JL, Combes A: New diagnostic and prognostic markers of ventilator-associated pneumonia. Curr Opin Crit Care 2006, 12:446-451

113. Conway Morris A, Kefala K, Wilkinson TS, Moncayo-Nieto OL, Dhaliwal K, Farrell L, Walsh TS, Mackenzie SJ, Swann DG, Andrews PJ, Anderson N, Govan JR, Laurenson IF, Reid H, Davidson DJ, Haslett C, Sallenave JM, Simpson AJ: Diagnostic importance of pulmonary interleukin-1beta and interleukin-8 in ventilator-associated pneumonia. Thorax 2010, 65:201-207.

114. Luyt $C E$, Combes A, Trouillet $J L$, Chastre J: Value of the serum procalcitonin level to guide antimicrobial therapy for patients with ventilator-associated pneumonia. Semin Respir Crit Care Med 2011, 32:181-187.

115. Pugh R, Grant C, Cooke RP, Dempsey G: Short-course versus prolongedcourse antibiotic therapy for hospital-acquired pneumonia in critically ill adults. Cochrane Database Syst Rev 2011:CD007577.

116. Goulden BE: Assessment of the usefulness of the examination of a gram smear of fresh uncentrifuged urine in the determination of significant bacteriuria in dogs. $N$ Z Vet J 1968, 16:1-2.

117. Jorgensen JH, Jones PM: Comparative evaluation of the Limulus assay and the direct Gram stain for detection of significant bacteriuria. Am J Clin Pathol 1975, 63:142-148.
118. Robins DG, Rogers KB, White RH, Osman MS: Urine microscopy as an aid to detection of bacteriuria. Lancet 1975, 1:476-478.

119. Crout FV, Tilton RC: Rapid screening of urine for significant bacteriuria by Gram stain, acridine orange stain, and the Autobac MTS system. Diagn Microbiol Infect Dis 1984, 2:179-186

120. Tilton RE, Tilton RC: Automated direct antimicrobial susceptibility testing of microscopically screened urine cultures. J Clin Microbio/ 1980, 11:157-161

121. Wilson ML, Gaido L: Laboratory diagnosis of urinary tract infections in adult patients. Clin Infect Dis 2004, 38:1150-1158.

122. Wiwanitkit V, Udomsantisuk N, Boonchalermvichian C: Diagnostic value and cost utility analysis for urine Gram stain and urine microscopic examination as screening tests for urinary tract infection. Urol Res 2005, 33:220-222.

123. Williams GJ, Macaskill P, Chan SF, Turner RM, Hodson E, Craig JC: Absolute and relative accuracy of rapid urine tests for urinary tract infection in children: a meta-analysis. Lancet Infect Dis 2010, 10:240-250.

124. Lewis JF, Alexander J: Microscopy of stained urine smears to determine the need for quantitative culture. J Clin Microbiol 1976, 4:372-374.

125. La Scola B, Raoult D: Direct identification of bacteria in positive blood culture bottles by matrix-assisted laser desorption ionisation time-offlight mass spectrometry. PLoS One 2009, 4:e8041.

126. Ferroni A, Suarez S, Beretti JL, Dauphin B, Bille E, Meyer J, Bougnoux ME, Alanio A, Berche P, Nassif X: Real-time identification of bacteria and Candida species in positive blood culture broths by matrix-assisted laser desorption ionization-time of flight mass spectrometry. J Clin Microbiol 2010, 48:1542-1548

127. Ferreira L, Sanchez-Juanes F, Gonzalez-Avila M, Cembrero-Fucinos D, Herrero-Hernandez A, Gonzalez-Buitrago JM, Munoz-Bellido JL: Direct identification of urinary tract pathogens from urine samples by matrixassisted laser desorption ionization-time of flight mass spectrometry. J Clin Microbiol 2010, 48:2110-2115.

128. Wang $X H$, Zhang G, Fan $Y Y$, Yang $X$, Sui WJ, Lu XX: Direct identification of bacteria causing urinary tract infections by combining matrix-assisted laser desorption ionization-time of flight mass spectrometry with UF-1000i urine flow cytometry. J Microbiol Methods 2013, 92:231-235.

129. Burillo A, Rodriguez-Sanchez B, Ramiro A, Cercenado E, Rodriguez-Creixems M, Bouza E: Gram-stain plus MALDI-TOF MS (matrix-assisted laser desorption ionization-time of flight mass spectrometry) for a rapid diagnosis of urinary tract infection. PLoS One 2014, 9:e86915.

130. Oakes AR, Badger R, Grove Dl: Comparison of direct and standardized testing of infected urine for antimicrobial susceptibilities by disk diffusion. J Clin Microbiol 1994, 32:40-45.

131. Kallenius G, Dornbusch K, Hallander HO, Jakobsson K: Comparison of direct and standardized antibiotic susceptibility testing in bacteriuria. Chemother 1981, 27:99-105.

132. Dupeyron CM, Guillemin GA, Leluan GJ: Rapid diagnosis of gram negative urinary infections: identification and antimicrobial susceptibility testing in 24 hours. J Clin Pathol 1986, 39:208-211.

133. Johnson JR, Tiu FS, Stamm WE: Direct antimicrobial susceptibility testing for acute urinary tract infections in women. J Clin Microbiol 1995, 33:2316-2323.

134. Gillenwater JY, Clark MM: Tentative direct antimicrobial susceptibility testing in urine. J Urol 1996, 156:149-153.

135. Bronnestam R: Direct antimicrobial susceptibility testing in bacteriuria. APMIS 1999, 107(4):437-444.

136. Breteler KB, Rentenaar RJ, Verkaart G, Sturm PD: Performance and clinical significance of direct antimicrobial susceptibility testing on urine from hospitalized patients. Scand J Infect Dis 2011, 43:771-776.

137. Baron EJ, Miller JM, Weinstein MP, Richter SS, Gilligan PH, Thomson RB Jr, Bourbeau P, Carroll KC, Kehl SC, Dunne WM, Robinson-Dunn B, Schwartzman JD, Chapin KC, Snyder JW, Forbes BA, Patel R, Rosenblatt JE, Pritt BS: A guide to utilization of the microbiology laboratory for diagnosis of infectious diseases: 2013 recommendations by the Infectious Diseases Society of America (IDSA) and the American Society for Microbiology (ASM). Clin Infect Dis 2013, 57:e22-e121.

138. Stevens DL, Bisno AL, Chambers HF, Everett ED, Dellinger P, Goldstein EJ, Gorbach SL, Hirschmann JV, Kaplan EL, Montoya JG, Wade JC: Practice guidelines for the diagnosis and management of skin and soft-tissue infections. Clin Infect Dis 2005, 41:1373-1406.

139. Wolk DM, Struelens MJ, Pancholi P, Davis T, Della-Latta P, Fuller D, Picton E Dickenson R, Denis O, Johnson D, Chapin K: Rapid detection of 
Staphylococcus aureus and methicillin-resistant S. aureus (MRSA) in wound specimens and blood cultures: multicenter preclinical evaluation of the Cepheid Xpert MRSA/SA skin and soft tissue and blood culture assays. J Clin Microbiol 2009, 47:823-826.

140. Dubouix-Bourandy A, de Ladoucette A, Pietri V, Mehdi N, Benzaquen D, Guinand R, Gandois JM: Direct detection of Staphylococcus osteoarticular infections by use of Xpert MRSA/SA SSTI real-time PCR. J Clin Microbiol 2011, 49:4225-4230.

141. Titecat M, Loiez C, Senneville E, Wallet F, Dezeque H, Legout L, Migaud H, Courcol RJ: Evaluation of rapid mecA gene detection versus standard culture in staphylococcal chronic prosthetic joint infections. Diagn Microbiol Infect Dis 2012, 73:318-321.

142. Petts DN, Lane A, Kennedy P, Hadfield SG, Mclllmurray MB: Direct detection of groups $A, C$ and $G$ streptococci in clinical specimens by a trivalent colour test. Eur J Clin Microbiol Infect Dis 1988, 7:34-39.

143. de Quirós JCL B, Moreno S, Muñoz P, Rodríguez-Créixems M, Catalán P, Bouza $\mathrm{E}$ : Antigen detection in the rapid diagnosis of severe extrapharyngeal infections caused by group A streptococcus. Infect Dis Clin Pract 1992, 1:372-376.

144. Garcia-Lechuz Moya JM: Clinical microbiological case: a Nicaraguan woman with skin lesions on the left elbow and foot. Clin Microbiol Infect 2001, 7:84-87.

145. Sinclair A, Xie X, Teltscher M, Dendukuri N: Systematic review and metaanalysis of a urine-based pneumococcal antigen test for diagnosis of community-acquired pneumonia caused by Streptococcus pneumoniae. J Clin Microbiol 2013, 51(7):2303-2310.

146. de Ory F, Minguito T: Comparison of five commercial assays for the detection of Legionella pneumophila antigens in urine. Enferm Infec Microbiol Clin 2009, 27(2):81-84

147. Emmadi R, Boonyaratanakornkit JB, Selvarangan R, Shyamala V, Zimmer BL, Williams L, Bryant B, Schutzbank T, Schoonmaker MM, Amos Wilson JA, Hall $L$, Pancholi P, Bernard K: Molecular methods and platforms for infectious diseases testing a review of FDA-approved and cleared assays. $J \mathrm{Mol}$ Diagn 2011, 13(6):583-604.

148. Tenover FC: Potential impact of rapid diagnostic tests on improving antimicrobial use. Ann N Y Acad Sci 2010, 1213:70-80.

doi:10.1186/s12879-014-0593-

Cite this article as: Burillo and Bouza: Use of rapid diagnostic techniques in ICU patients with infections. BMC Infectious Diseases 2014 14:593.

\section{Submit your next manuscript to BioMed Central and take full advantage of:}

- Convenient online submission

- Thorough peer review

- No space constraints or color figure charges

- Immediate publication on acceptance

- Inclusion in PubMed, CAS, Scopus and Google Scholar

- Research which is freely available for redistribution 